Bond University

Research Repository

\title{
Recreational ecstasy use and the neurotoxic potential of MDMA: Current status of the controversy and methodological issues
}

\author{
Lyvers, Michael
}

\author{
Published in: \\ Drug and Alcohol Review
}

DOI:

$10.1080 / 09595230600657758$

\section{Licence:}

Other

Link to output in Bond University research repository.

Recommended citation(APA):

Lyvers, M. (2006). Recreational ecstasy use and the neurotoxic potential of MDMA: Current status of the controversy and methodological issues. Drug and Alcohol Review, 25(3), 269-276.

https://doi.org/10.1080/09595230600657758

\section{General rights}

Copyright and moral rights for the publications made accessible in the public portal are retained by the authors and/or other copyright owners and it is a condition of accessing publications that users recognise and abide by the legal requirements associated with these rights.

For more information, or if you believe that this document breaches copyright, please contact the Bond University research repository coordinator. 
Recreational Ecstasy Use and the Neurotoxic Potential of MDMA: Current Status of the Controversy and Methodological Issues

Michael Lyvers, Ph.D.

Department of Psychology

Bond University

Gold Coast, Qld 4229 Australia

Phone (61) (75) 5952565

$\operatorname{Fax}(61)(75) 5952672$

e-mail mlyvers@staff.bond.edu.au 


\begin{abstract}
The controversy over possible MDMA-induced serotonergic neurotoxicity in human recreational Ecstasy users is critically examined in light of recent research findings. Although the designs of such studies have improved considerably since the 1990s, the evidence to date remains equivocal for a number of reasons, including (1) inconsistent findings on the existence and reversibility of persistent Ecstasy-related serotonergic and cognitive deficits; (2) lack of clear association between changes in brain imaging measures and functional deficits attributed to MDMA-induced neurotoxicity; (3) the contribution of concomitant cannabis or other drug use to both brain imaging abnormalities and cognitive deficits; (4) methodological shortcomings such as failure to adequately match samples of Ecstasy users and controls; (5) the questionable relevance of animal models of MDMA-induced neurotoxicity to typical human patterns of Ecstasy use; and (6) the potential role of inherent pre-drug deficits in serotonergic systems, impulse control and executive cognitive function that may predispose to excessive use of drugs including Ecstasy. Given the retrospective nature of nearly all studies of Ecstasy users to date, the controversy over whether MDMA has ever caused neurotoxicity or cognitive deficit in human Ecstasy users is likely to continue for some time without resolution.
\end{abstract}

KEYWORDS: Ecstasy, neurotoxicity, serotonin, cognition 
Recreational Ecstasy Use and the Neurotoxic Potential of MDMA: Current Status of the Controversy and Methodological Issues

Ecstasy is the popular term for the serotonin-releasing agent 3,4-methylenedioxymethamphetamine (MDMA), a widely abused illicit drug with mixed stimulant and mild hallucinogenic actions. According to the 2001 National Drug Strategy Household Survey, 20\% of Australians aged 20-29 have used Ecstasy, a significant increase since the previous (1998) survey. The widespread use of Ecstasy by young Australian adults naturally raises concern over the health consequences of such behaviour. Ecstasy is commonly taken at dance clubs or "rave" venues where the mild hallucinogenic effect of the drug enhances the subjective impact of the music and social environment. In contrast to such well-known "recreational" use, some researchers and clinicians in the U.S. and Europe have quietly supported limited therapeutic applications of MDMA (eg., for cancer-related anxiety, post-traumatic stress disorder, severe depression, Parkinsonism; see Holland, 2001), and the FDA has recently granted approval for clinical trials of the drug (Check, 2004). Although MDMA-induced fatalities are extremely rare (Cole \& Sumnall, 2003), public fears about MDMA-induced brain damage and persistent cognitive dysfunction have been triggered by widely publicised research suggesting that (1) MDMA can cause lasting disruptions to the serotonergic system, and (2) Ecstasy use is commonly associated with deficient cognitive and memory performance. The possibility of cumulative brain damage as the drug is used repeatedly or heavily over time presents an alarming prospect. However, the following critical review of the recent research literature on this controversial topic suggests that such alarm may be unwarranted.

\section{MDMA-Induced Neurotoxicity: A Summary of the Evidence}

In animal studies using rodents and primates, repeated high doses of MDMA caused signs of lasting damage to serotonergic axons in regions such as the prefrontal cortex and hippocampus (eg., Battaglia et al., 1991; Callahan, Cord \& Ricaurte, 2001; Ricaurte et al, 1988; Sabol et al., 1996). Long-term recovery appears to be only partial, with abnormal patterns of reinnervation and incomplete restoration of forebrain serotonin levels (Hatzidimitriou, McCann \& Ricaurte, 1999). 
MDMA stimulates release of serotonin and also blocks reuptake of other monoamines (Parrott, 2001), however the acute serotonin-releasing action appears to be largely responsible for the unique “entactogenic" psychological effects of the drug (Liechti \& Vollenweider, 2001). Although adverse reactions to typical doses of Ecstasy are relatively rare in human Ecstasy users (Gowing et al., 2002), the research findings in animals of serotonergic neurotoxicity induced by MDMA in brain regions such as the hippocampus and prefrontal cortex are disturbing given the central role of these areas in memory and executive cognitive functioning in humans and the involvement of the serotonin system in regulation of mood and impulse control. Thus since the initial work on animals, a substantial number of studies of human recreational Ecstasy users have reported significantly poorer verbal and/or visual memory (eg., Back-Madruga et al., 2003; Bhattachary \& Powell, 2001; Bolla, McCann \& Ricaurte, 1998; Fox, Parrott \& Turner, 2001; Fox, Toplis \& Parrott, 2001; Fox et al., 2002; Gouzoulis-Mayfrank et al., 2003; Hanson \& Luciana, 2004; McCann et al., 1999; Morgan, 1999; Morgan et al., 2002; Parrott et al., 1998; Reneman, 2000; Reneman et al., 2001), prospective or everyday memory (Heffernan et al., 2001; Rodgers et al., 2001; Zakzanis, Young \& Campbell, 2003) and/or executive cognitive functioning (eg., Bhattachary \& Powell, 2002; Halpern et al., 2004; Hanson \& Luciana, 2004; Heffernan et al., 2001; Morgan et al., 2002; Thomasius et al., 2003; Wareing, Fisk \& Murphy, 2000; Zakanis \& Young, 2001a) in Ecstasy users compared to controls, with some studies reporting differences on measures of mood, psychopathology and impulsivity as well (eg., Moeller et al., 2002; Morgan et al., 2002; Thomasius et al., 2003; Wareing et al., 2000). Moreover, brain imaging studies of human Ecstasy users have reported deficiencies in cerebral metabolism (Obrocki et al., 2002), serotonin transporter densities (McCann et al., 1998; Reneman et al., 2001) and N-acetylaspartate/creatine ratios (Reneman et al., 2002) in heavy Ecstasy users compared to controls, interpreted as reflecting cumulative MDMA-induced damage to the serotonergic system (also see Gouzoulis-Mayfrank, Dauman \& Sass, 2002).

Although the evidence summarised above would seem to present a solid case for neurotoxic effects of MDMA and corresponding adverse functional consequences in human Ecstasy users, 
such conclusions are questionable for a number of reasons. These include inconsistent findings on the existence and reversibility of persistent Ecstasy-related serotonergic and cognitive deficits; lack of clear association between changes in brain imaging measures and functional deficits attributed to MDMA-induced neurotoxicity; the contribution of concomitant cannabis or other drug use to both brain imaging abnormalities and cognitive deficits; methodological shortcomings, such as failure to adequately match samples of Ecstasy users and controls; the questionable relevance of animal models of MDMA-induced neurotoxicity to typical human patterns of Ecstasy use; and the potential role of inherent pre-drug deficits in serotonergic systems, impulse control and executive cognitive function that may predispose to excessive use of drugs including Ecstasy. These issues are reviewed below.

\section{Are Ecstasy-Associated Deficits Reversible?}

One unresolved issue is the degree of reversibility of the reported deficits. Most earlier brain imaging studies compared recently (1-2 weeks) abstinent Ecstasy users to non-user controls, leaving open the question of long-term improvement or recovery. More recent brain imaging studies that compared recently abstinent current users of Ecstasy versus long-term abstinent former users have reported strong evidence for reversibility of the deficiencies in serotonin transporter densities commonly observed in recently abstinent users (Buchert et al., 2003; Reneman et al., 2001; Thomasius et al., 2003), suggesting that such deficiencies are attributable to short-term functional down-regulation rather than neurotoxicity. Serotonergic deficits (including reduction in serotonin transporter densities) are also well-known effects of antidepressant therapy with tricyclics and SSRIs (Grob, 2000), and may reflect brain changes associated with the therapeutic effects of such drugs rather than neurotoxicity. Nevertheless, despite the apparent reversibility of the reduction in serotonin transporter densities in recent users compared to former Ecstasy users and non-user controls, verbal memory was impaired in both recent and former users in the Reneman et al. brain imaging study. Similarly, both recent and former Ecstasy users were impaired on indices of executive cognitive functioning compared to controls in a study by Wareing at al. (2000), and 
Ecstasy users scored higher on anxiety than controls. Morgan et al. (2002) found elevated psychopathology and impulsivity scores, and poorer executive cognitive and verbal recall performance on some (but not all) measures, in both recent and former users compared to controls. A combination of reversible and irreversible deficits in memory performance was indicated in a study of recent users, former users and non-user controls by Bhattachary and Powell (2001). In the Thomasius et al. brain imaging study, both recent and former Ecstasy users scored higher on depression and other measures of psychopathology than non-user controls, and former users exhibited poorer verbal memory performance than controls, again suggesting that functional deficits may not be fully reversible despite the apparent reversibility of Ecstasy-related differences on brain imaging measures. The poorer memory performance of former but not recent users compared to controls as reported by Thomasius et al. could be attributable to differences in overall lifetime drug use between the Ecstasy user samples, given that former Ecstasy users reported considerably higher use of cannabis than recent Ecstasy users and both polydrug user and non-user controls. This raises another problem: the possible contribution of cannabis or other drug use to the observed deficits in Ecstasy users (see below).

Are Cognitive Deficits of Ecstasy Users Due to Serotonergic Neurotoxicity?

Recent findings cited above appear to suggest that memory and executive cognitive performance measures reveal more subtle and enduring deficits than are currently detectable with brain imaging techniques. In any case the methods that have been used to image serotonergic axon terminals in brain imaging studies of Ecstasy users have been extensively criticised (see Kish, 2002, on the issue of specificity of ligands used to measure serotonin transporter densities). More importantly, research on nonhuman primates has generally found that MDMA-induced serotonergic neurotoxicity is not associated with decrements in memory performance even when $50-99 \%$ of brain serotonin is permanently depleted (Taffe et al., 2002; Winsauer et al., 2002). The diet drug fenfluramine produces the same signs of serotonergic neurotoxicity in animals as MDMA (Bowyer et al., 2003), yet has been administered to $25,000,000$ people over several decades with no evidence 
of any associated deficits (Grob, 2000). Thus perhaps a more plausible interpretation of the many reports of memory and cognitive deficits associated with Ecstasy use is that they are not due to MDMA-induced neurotoxicity, a conclusion reached in a recent review by Cole and Sumnall (2003). Certain psychopathological characteristics (eg., obsessive-compulsiveness, impulsivity, anxiety, depression) also appear to distinguish both recent and former Ecstasy users from non-user controls in some of the studies cited above. But a significant problem with many studies reporting brain abnormalities or functional deficits in Ecstasy users is that comparison of Ecstasy users to illicit-drug-naive controls was likely confounded by use of other drugs - especially cannabis, as Ecstasy users tend to use cannabis as well, often extensively.

\section{The Cannabis Confound}

A recent physiological study (Gouzoulis-Mayfrank et al., 2002) found that the prolactin response to fenfluramine challenge, an index of serotonergic system functioning, was more affected by past cannabis use than by Ecstasy use, an unexpected result. More importantly, heavy cannabis use has recently been shown to be associated with executive cognitive dysfunction and deficits on tests of visual and verbal memory that were previously found to differentiate Ecstasy users from controls; the cannabis-related deficits persisted for at least one month of abstinence (Bolla et al., 2002). The recent findings by Bolla et al., as well as an earlier report of slowly reversible adverse effects of cannabis on verbal memory (Pope et al., 2001), suggest that at least some of the widely reported deficits in memory and executive cognitive performance in Ecstasy users - especially heavy users (who also tend to be heavy users of cannabis) - might be attributable to heavy use of cannabis rather than Ecstasy. Some recent studies that have attempted to control for cannabis use in Ecstasy users have indeed reported that certain indices of memory impairment, executive cognitive dysfunction or psychopathology were more strongly related to use of cannabis than Ecstasy (Barker \& Lyvers, 2002; Croft et al., 2001b; Dafters et al., 2004; Daumann et al., 2001; Morgan et al., 2002; Simon \& Mattick, 2002), whereas other studies have indicated that Ecstasy use contributes to some memory and executive cognitive deficits as well as certain psychopathology measures 
independently of cannabis or other drug use (Fox et al., 2001ab, 2002; Heffernan et al., 2001;

Morgan et al., 2002; Rodgers et al., 2001). For example, Morgan et al. found that most indices of psychopathology related more strongly to cannabis use than Ecstasy use, with the exception of obsessive-compulsiveness, anxiety, somatization and overall symptom severity, which were more strongly related to Ecstasy use; poorer immediate and delayed verbal memory and executive cognitive dysfunction were related to Ecstasy use but not cannabis use. By contrast, Barker and Lyvers (2002) found that immediate and delayed verbal recall and immediate and delayed logical memory test scores were all significantly worse in Ecstasy users than polydrug user controls until level of prior cannabis use was controlled by covariate analysis, in which case the association of Ecstasy use with memory impairment disappeared entirely; measures of various forms of psychopathology and executive cognitive functioning failed to distinguish Ecstasy users from polydrug controls. Further work by Lyvers, Barker and Bradnam (2003) found that after controlling for cannabis use, Ecstasy users scored worse than controls only on obsessive-compulsiveness and phobic anxiety, both of which have been linked to serotonergic dysfunction (Gurtman et al., 2002; Hollander et al., 1992). A single, small-scale longitudinal study of Ecstasy users (Zakzanis \& Young, 2001b) found that memory performance worsened after one year of continued Ecstasy use, but use of various other illicit drugs also increased over the same period, calling into question any conclusions about the effect of Ecstasy use on memory. The relative contribution of Ecstasy versus cannabis or other drug use to reported memory and cognitive deficits or psychopathology in Ecstasy users remains unresolved (eg., see recent meta-analysis of Ecstasy vs. cannabis effects on memory by Verbaten, 2003).

\section{Premorbid Factors Associated with Drug Use}

A further, and perhaps more serious problem with retrospective studies of drug users is that pre-drug deficiencies in brain serotonergic functioning may constitute an inherent risk factor for alcohol or illicit drug abuse as well as for impulsivity, depression, obsessive-compulsive disorder, and executive cognitive dysfunction (eg., Cloninger, 1987; Conrod, Peterson \& Pihl, 1997; 
Giancola et al., 1996; Higley \& Linnoila, 1997; LeMarquand et al., 1998; Lyvers, 2000; Nielsen et al., 1998; Pihl et al., 1995; Tarter, Moss \& Vanyukov, 1995; Virkkunen \& Linnoila, 1997). Thus reported differences between Ecstasy or other drug users and non-substance-abusing controls on various measures, especially indices of executive cognitive functioning and impulsivity, may reflect pre-drug traits rather than effects of Ecstasy or other drug use, particularly when heavy users are examined (Croft et al., 2001a; Kish, 2002). Croft et al. attempted to address this issue in a physiological study. They reported differences between Ecstasy users and cannabis users on an EEG measure (intensity dependence of auditory evoked potentials) that they considered to be sensitive to serotonergic system functioning; the presumed serotonergic deficit was related to total Ecstasy consumption but not frequency of use, which Croft et al. tentatively interpreted as consistent with MDMA-induced serotonergic neurotoxicity rather than premorbid characteristics (such as depression) that might have promoted frequent self-medication. However, the increased risk of drug abuse associated with deficient pre-drug serotonergic functioning is generally not attributed to self-medication tendencies but rather to personality traits such as impulsivity and disinhibition, which can promote bingeing behaviour that could easily account for the relationship reported by Croft et al. (see Lyvers, 2000). Further, as noted above, most recent research comparing Ecstasy users to Ecstasy-naive cannabis or polydrug users on indices of memory, executive cognitive functioning and psychopathology has yielded mixed findings. Only if Ecstasy users consistently show signs of enduring brain dysfunction or poor memory or cognitive performance that clearly differentiates them from other substance abusers - especially when level of use of other drugs such as cannabis, methamphetamine or alcohol is carefully matched or otherwise controlled can the case for functional neurotoxic sequelae of recreational Ecstasy use become tenable. In the absence of any such evidence, the apparent association between heavy use of Ecstasy and cognitive impairment is most plausibly attributable to pre-drug traits associated with an increased risk of substance abuse. This argument also applies to similar recent reports of enduring deficits associated with heavy cannabis use (Bolla et al., 2002; Pope et al., 2003). 


\section{Other Methodological Problems}

A common methodological criticism of research on recreational Ecstasy users concerns the retrospective nature of the reports of "MDMA" use by participants in such studies (Cole \& Sumnall, 2003; Curran, 2000; Grob, 2000; Hurley, Reneman \& Taber, 2002). The actual content of pills sold as "Ecstasy" on the black market has been reported to vary, with some samples containing neither MDMA nor the similar drug MDEA but dissimilar drugs such as methamphetamine (known to be neurotoxic in high doses; Ricaurte et al., 2003), ketamine (an NMDA antagonist which can be neurotoxic in laboratory animals; Olney et al., 1991) or the over-the-counter cough suppressant dextromethorphan (which in large doses is hallucinogenic and probably neurotoxic like other NMDA antagonists). Thus any deficits exhibited by Ecstasy users may be attributable to the enduring effects of other neurotoxins sold as MDMA, rather than MDMA itself. However, recent analyses of large seizures of Ecstasy in the UK have indicated that all samples did contain effective doses of MDMA (Cole et al., 2002), and a recent analysis of blood and urine samples from "rave" party attendees in Australia revealed that all participants who said they had taken "Ecstasy" showed high levels of MDMA (Irvine et al., 2003). A recent review (Parrott, 2004) concluded that illicit samples of Ecstasy now contain effective doses of MDMA in $90-100 \%$ of cases. Thus it is likely that at least some recent samples of Ecstasy users included a significant proportion who had been exposed to effective (and even possibly neurotoxic) doses of MDMA rather than, or perhaps in addition to, other potentially neurotoxic substances. Other methodological criticisms of research on Ecstasy users include the confounding influence of unequal gender ratios and other demographic differences (such as education level) between user and control groups in many studies. Females have been reported to have $25 \%$ lower serotonin transporter densities than males irrespective of drug use (Kish, 2002; Mann et al., 2000), and show a different brain response to MDMA than males (Liechti, Gamma \& Vollenweider, 2001), thus brain imaging and other investigations of the serotonin system in Ecstasy users should aim to achieve gender balance between user and control groups. Age, education level and general "premorbid" intelligence (eg., as estimated by reading 
scores; Barker \& Lyvers, 2002) should also be matched between groups, as should alcohol intake given the abundant evidence of brain shrinkage and cognitive decline associated with chronic heavy alcohol abuse (see Lyvers, 2000).

Are Animal Models Relevant?

A final contentious issue concerns the assumption that animal models of MDMA-induced serotonergic neurotoxicity are actually relevant to typical human use of Ecstasy. This assumption can be questioned given the necessity of administering extremely high repeated doses to rats or primates over a short time interval in order to induce neurotoxicity - cumulative doses that are considerably higher than those taken by human Ecstasy users even after considering interspecies scaling of doses (Aghajanian \& Lieberman, 2001; Cole et al., 2002; Grob, 2000). Exposure to neurotoxic dosing regimens may only occur in the most extreme users of Ecstasy, if at all; hence recent and former Ecstasy users should be carefully assessed on the extent of their recent or past Ecstasy use, taking into account factors such as the highest dose taken, the typical dose taken, the number of doses taken per occasion, and the number of prior occasions of Ecstasy use. Although the dose of MDMA per Ecstasy tablet varies widely, this approach would nevertheless help evaluate whether any observed Ecstasy-related deficits might plausibly reflect either cumulative or suprathreshold, high-dose exposure to the drug's potential neurotoxic effect as indicated by animal studies.

\section{Conclusion: Do We Want Ecstasy to Cause Brain Damage?}

Recently a widely publicised claim of severe dopaminergic neurotoxicity induced by MDMA in primates (Ricaurte et al, 2002) was retracted (to the authors' credit) when the researchers discovered that the vial supposedly containing MDMA was actually methamphetamine, which is known to be neurotoxic to dopamine neurons at the extremely high doses administered as "MDMA" in the study (the effective dose of methamphetamine is considerably lower than that of MDMA). Subsequent experiments using actual MDMA revealed no signs of dopaminergic neurotoxicity in primates even at very high doses (Ricaurte et al., 2003). Other claims of Ecstasy-induced 
Parkinsonism have been convincingly refuted (Kish et al., 2000; Kish, 2003). At present the controversy concerning possible neurotoxic sequelae of recreational MDMA/Ecstasy use is limited to the drug's purported actions on the serotonin system as revealed by high-dose studies in animals, but the Ricaurte et al. mislabelling incident has arguably cast a shadow over all prior claims of Ecstasy-induced brain damage. The fact that the prestigious journal Science rushed to publish Ricaurte et al.'s highly implausible initial report has been attributed to the widespread desire of researchers and government agencies to find scientific reasons to condemn Ecstasy use (Nature Editorial, 2003). Claims of Ecstasy-induced brain damage have all too often been uncritically reported in the popular media and by various "experts" in an effort to generate alarm or scare young people away from using or trying Ecstasy. Past experience with claims of "reefer madness" suggests that such an approach to preventing illicit drug use only serves to undermine the credibility of the relevant authorities, a case of "crying wolf" that may later backfire. For this reason, claims of MDMA-induced neurotoxicity and associated cognitive deficits or other problems in Ecstasy users must be carefully and dispassionately scrutinized. At present, the accumulated evidence for such claims is not compelling.

On purely scientific grounds the ideal investigation of the neurotoxic potential of MDMA in humans would administer various doses of the drug to Ecstasy-naive volunteers, with brain and behavioral changes measured at various times following MDMA exposure in order to assess their reversibility. A preliminary brain imaging study by Vollenweider, Jones and Baggott (2001) administered a moderate dose of MDMA (1.5-1.7 mg/ $/ \mathrm{kg})$ to Ecstasy-naive volunteers and found no changes in serotonin transporter densities (using PET) from pre-drug baseline to one month after MDMA administration. A related study found no changes in memory and cognitive performance at one month post-MDMA treatment (Ludewig et al., 2003). The research was conducted in Switzerland where restrictions on administration of illicit drugs to humans for research purposes are less stringent than in most other countries. However, the sample size was small and limited to males, and dosing regimens shown to be neurotoxic in nonhuman primates were not used. More 
recently, limited clinical trials of MDMA for post-traumatic stress disorder and for anxiety in terminal cancer patients have been approved in the U.S. (Check, 2004). Nevertheless, given the legal and ethical issues involved in administering MDMA to humans, studies of retrospectively self-reported Ecstasy use will continue to be the most common approach for investigating Ecstasy's possible long-term effects in humans. Unfortunately, for reasons outlined above, the collective research findings arising from such work are likely to remain equivocal, provoking much discussion and debate but little insight into the nature of any observed differences between users and non-users of Ecstasy. 
References

Aghajanian, G.K., \& Lieberman, J.A. (2001). Response. Neuropsychopharmacology, 24, 335-336.

Back-Madruga, C., Boone, K.B., Chang, L., Grob, C.S., Lee, A., Nations, H., \& Poland, R.E. (2003). Neuropsychological effects of 3,4-methylenedioxymethamphetamine (MDMA or ecstasy) in recreational users. Clinical Neuropsychologist, 17, 446-459.

Barker, B., \& Lyvers, M. (2002). Neuropsychological performance in human ecstasy users: A test of the ecstasy-induced serotonin neurotoxicity hypothesis. Presented at the Annual Convention of the Australian Psychological Society, Gold Coast, Australia, September 2002.

Battaglia, G., Sharkey, J., Kuhar, M.J., \& de Souza, E.B. (1991). Neuroanatomic specificity and time course of alterations in rat brain serotonergic pathways induced by MDMA (3,4-methylenedioxymethamphetamine): Assessment using quantitative autoradiography. Synapse, 8, 249-260.

Bhattachary, S., \& Powell, J.H. (2001). Recreational use of MDMA or “ecstasy”: Evidence for cognitive impairment. Psychological Medicine, 31, 647-658.

Bolla, K.I., Brown, K., Eldreth, D., Tate, K., \& Cadet, J.L. (2002). Dose-related neurocognitive effects of marijuana use. Neurology, 59, 1337-1343.

Bolla, K.I., McCann, U., \& Ricaurte, G.A. (1998). Memory impairment in abstinent MDMA (“ecstasy”) users. Neurology, 51, 1532-1537.

Bowyer, J.F., Young, J.F., Slikker, W., Itzak, Y., Mayorga, A.J., Newport, G.D., Ali, S.F., Frederick, D.L., \& Paule, M.G. (2003). Plasma levels of parent compound and metabolites after doses of either d-fenfluramine or d-3,4-methylenedioxymethamphetamine (MDMA) that produces long-term serotonergic alterations. Neurotoxicology, 24, 379-390.

Buchert, R., Thomasius, R., Nebeling, B., Petersen, K., Obrocki, J., Jenicke, L., Wilke, F., Wartberg, L., Zapletalova, P., \& Clausen, M. (2003). Long-term effects of "Ecstasy" use on serotonin transporters of the brain investigated by PET. Journal of Nuclear Medicine, 44, $375-$ 384. 
Callahan, B.T., Cord, B.J., \& Ricaurte, G.A. (2001). Long-term impairment of anterograde axonal transport along fiber projections originating in the rostral raphe nuclei after treatment with fenfluramine or MDMA. Synapse, 40, 113-121.

Check, E. (2004). The ups and downs of ecstasy. Nature, 429, 126-128.

Cloninger, C.R. (1987). Neurogenetic adaptive mechanisms in alcoholism. Science, 23, 410-415.

Cole, J.C., Bailey, M., Sumnall, H.R., Wagstaff, G.F., \& King, L.A. (2002). The content of ecstasy tablets: Implications for the study of their long-term effects. Addiction, 97, 1531-1536.

Cole, J.C., \& Sumnall, H.R. (2003). Altered states: The clinical effects of ecstasy. Pharmacology \& Therapeutics, 98, 35-58.

Conrod, P.J., Peterson, J.B., \& Pihl, R.O. (1997). Disinhibited personality and sensitivity to alcohol reinforcement: Independent correlates of drinking behavior in sons of alcoholics. Alcoholism:

Clinical \& Experimental Research, 21, 1320-1332.

Croft, R.J., Klugman, A., Baldeweg, T., \& Gruzelier, J.H. (2001a). Electrophysiological evidence of serotonergic impairment in long-term MDMA (“ecstasy”) users. American Journal of Psychiatry, $158,1687-1692$.

Croft, R.J., Mackay, A.J., Mills, A.T.D., \& Gruzelier, J.G.H. (2001b). The relative contribution of ecstasy and cannabis to cognitive impairment. Psychopharmacology, 153, 373-379.

Curran, H.V. (2000). Is MDMA ("Ecstasy") neurotoxic in humans? An overview of evidence and methodological problems in research. Neuropsychobiology, 42, 34-41.

Dafters, R.I., Hoshi, R., \& Talbot, A.C. (2004). Contribution of cannabis and MDMA (“ecstasy”) to cognitive changes in long-term polydrug users. Psychopharmacology (Berlin), 173, 405-410.

Daumann, J., Pelz, S., Becker, S., Tuchtenhagen, F., \& Gouzoulis-Mayfrank, E. (2001).

Psychological profile of abstinent recreational Ecstasy (MDMA) users and significance of concomitant cannabis use. Human Psychopharmacolog: Clinical and Experimental, 16, 627-633.

Fox, H.C., Parrott, A.C., \& Turner, J.J.D. (2001a). Ecstasy use: Cognitive deficits related to dosage rather than to self-reported problematic use of the drug. Journal of Psychopharmacology, 15, 273- 
281.

Fox, H.C., Toplis, J.J.D., \& Parrott, A.C. (2001b). Auditory verbal learning in drug-free polydrug users. Human Psychopharmacology: Clinical and Experimental, 16, 613-618.

Fox, H.C., McLean, A., Turner, J.J., Parrott, A.C., Rogers, R., \& Sahakian, B.J. (2002).

Neuropsychological evidence of a relatively selective profile of temporal dysfunction in drug-free MDMA (“ecstasy”) polydrug users. Psychopharmacology, 162, 203-214.

Giancola, P.R., Martin, C.S., Tarter, R.E., Pelham, W.E., \& Moss, H.B. (1996). Executive cognitive functioning and aggressive behavior in preadolescent boys at high risk for substance abuse/dependence. Journal of Studies on Alcohol, 57, 352-359.

Gouzoulis-Mayfrank, E., Daumann, J., \& Sass, H. (2002). Long-term neurotoxic brain damage in ecstasy (MDMA) users. A review of the literature. Nervenarzt, 73, 405-421.

Gouzoulis-Mayfrank, E., Becker, S., Pelz, S., Tuchtenhagen, F., \& Daumann, J. (2002).

Neuroendocrine abnormalities in recreational ecstasy (MDMA) users: Is it ecstasy or cannabis? Biological Psychiatry, 51, 766-9.

Gouzoulis-Mayfrank, E., Thimm, B., Rezk, M., Hensen, G., \& Daumann, J. (2003). Memory impairment suggests hippocampal dysfunction in abstinent ecstasy users. Progress in NeuroPsychopharmacology and Biological Psychiatry, 27, 819-827.

Gowing, L.R., Henry-Edwards, S.M., Irvine, R.J., \& Ali, R.L. (2002). The health effects of ecstasy: A literature review. Drug and Alcohol Review, 21, 53-63.

Grob, C. (2000). Deconstructing ecstasy: The politics of MDMA research. Addiction Research, 8, $549-588$.

Gurtman, C.G., Morley, K.C., Li, K.M., Hunt, G.E., \& McGregor, I.S. (2002). Increased anxiety in rats after MDMA: Association with serotonin depletion. European Journal of Pharmacology, 446, 89-96.

Halpern, J.H., Pope, H.G., Sherwood, A.R., Barry, S., Hudson, J.I., \& Yurgelun-Todd, D. (2004). Residual neuropsychological effects of illicit 3,4-methelenedioxymethamphetamine (MDMA) in 
individuals with minimal exposure to other drugs. Drug and Alcohol Dependence, in press.

Hanson, K.L., \& Luciana, M. (2004). Neurocognitive function in users of MDMA: The importance of clinically significant patterns of use. Psychological Medicine, 34, 229-246.

Hatzidimitriou, G., McCann, U.D., \& Ricaurte, G.A. (1999). Altered serotonin innervation patterns in the forebrain of monkeys treated with (+/-)3,4-methylenedioxymethamphetamine seven years previously: Factors influencing abnormal recovery. Journal of Neuroscience, 19, 5096-5107.

Heffernan, T.M., Jarvis, H., Rodgers, J., Scholey, A.B., \& Ling, J. (2001). Prospective memory, everyday cognitive failure and central executive function in recreational users of Ecstasy. Human Psychopharmacology: Clinical and Experimental, 16, 607-612.

Higley, J.D., \& Linnoila, M. (1997). A nonhuman primate model of excessive alcohol intake: Personality and neurobiological parallels of Type I- and Type II-like alcoholism. In M. Galanter (Ed.), Recent developments in alcoholism, volume 13: Alcohol and violence (pp. 191-219). New York: Plenum Press.

Holland, J. (Ed.) (2001). Ecstasy: The complete guide. Rochester, VT: Park Street Press.

Hollander, E., DeCaria, C.M., Nitescu, A., Gully, R., Suckow, R.F., Cooper, T.B., Gorman, J.M., \& Liebowitz, M.R. (1992). Serotonergic function in obsessive-compulsive disorder. Archives of General Psychiatry, 49, 21-28.

Hurley, R.A., Reneman, L., \& Taber, K.H. (2002). Ecstasy in the brain: A model for neuroimaging. Journal of Neuropsychiatry \& Clinical Neurosciences, 14, 125-129.

Irvine, R., Keane, M., Felgate, P., Callaghan, P., \& White, J. (2003). Blood drug concentrations and clinical status of dance party participants. Presented at the Annual Meeting of the Australasian Society of Clinical \& Experimental Pharmacologists and Toxicologists, Sydney, Australia, December 2003.

Kish, S.J. (2002). How strong is the evidence that brain serotonin neurons are damaged in human users of ecstasy? Pharmacology, Biochemistry and Behavior, 71, 845-8551.

Kish, S.J. (2003). What is the evidence that ecstasy (MDMA) can cause Parkinson's Disease? 
Movement Disorders, 18, 1219-1223.

Kish, S.J., Furukawa, Y., Ang, L., Vorce, B.S., \& Kalasinsky, K.S. (2000). Striatal serotonin is depleted in brain of a human MDMA (ecstasy) user. Neurology, 55, 294-296.

LeMarquand, D.G., Pihl, R.O., Young, S.N., Tremblay, R.E., Seguin, J.R., Palmour, R.M., \& Benkelfat, C. (1998). Tryptophan depletion, executive functions, and disinhibition in aggressive, adolescent males. Neuropsychopharmacology, 19, 333-341.

Liechti, M., Gamma, A., \& Vollenweider, F. (2001). Gender differences in the subjective effects of MDMA. Psychopharmacology, 154, 161-168.

Liechti, M.E., \& Vollenweider, F.X. (2001). Which neuroreceptors mediate the subjective effects of MDMA in humans? A summary of mechanistic studies. Human Psychopharmacology: Clinical and Experimental, 16, 589-598.

Ludewig, S., Ludewig, K., Hasler, F., \& Vollenweider, F.X. (2003) No lasting effects of moderate doses of MDMA (Ecstasy) on memory performance and mood states in healthy humans. Biological Psychiatry, 53 (Suppl), 205S.

Lyvers, M. (2000). "Loss of control” in alcoholism and drug addiction: A neuroscientific interpretation. Experimental and Clinical Psychopharmacology, 8, 225-249.

Lyvers, M., Barker, B., \& Bradnam, J. (2003). Memory, cognition, mood and impulsivity in current and former users of MDMA (ecstasy): Testing the serotonergic neurotoxicity hypothesis. Journal of Psychosomatic Research, 55, 156-7.

Mann, J.J., Huang, Y.Y., Underwood, M.D., Kassir, S.A., Oppenheim, S., Kelly, T.M., Dwork, A.J., \& Arango, V. (2000). A serotonin transporter gene promoter polymorphism (5-HTTLPR) and prefrontal cortical binding in major depression and suicide. Archives of General Psychiatry, 57, 729-738.

McCann, U.D., Merti, M., Eligulashvii, V., \& Ricaurte, G.A. (1999). Cognitive performance in (+/-) 3,4-methylenedioxymethamphetamine (MDMA, “ecstasy”)users: A controlled study. Psychopharmacology, 143, 417-425. 
McCann, U.D., Szabo, Z., Scheffel, U., Dannals, R.F., \& Ricaurte, G.A. (1998). Positron emission tomography evidence of toxic effect of MDMA ("ecstasy”) on brain serotonin neurons in human beings. Lancet, 352, 1433-1437.

Moeller, F.G., Dougherty, D.M., Steinberg, J.L., Swann, A.C., Silverman, P.B., Ruiz, P., \& Barratt, E.S. (2002). Heavy "ecstasy" use is associated with increased impulsivity. Addictive Disorders, 1 , 47-52.

Morgan, M.J. (1999). Memory deficits associated with recreational use of ecstasy (MDMA). Psychopharmacology, 141, 30-36.

Morgan, M.J., McFie, L., Fleetwood, L.H., \& Robinson, J.A. (2002). Ecstasy (MDMA): Are the psychological problems associated with its use reversed by prolonged abstinence? Psychopharmacology, 159, 294-303.

National Drug Strategy Household Survey, 2001. Canberra: Australian Institute of Health and Welfare, Department of Health and Aged Care.

Nature Editorial (2003, September 18). Ecstasy's after effects: Following the retraction of a highprofile paper, the US research agency that supports research on drug abuse needs to ensure its independence from intense political pressure to prove that recreational drugs are harmful. Nature, $425,223$.

Nielsen, D.A., Virkkunen, M., Lappalainen, J., Eggert, M., Brown, G.L., Long, J.C., Goldman, D., \& Linnoila, M. (1998). A tryptophan hydroxylase gene marker for suicidality and alcoholism. Archives of General Psychiatry, 55, 593-602.

Obrocki, J., Schmoldt, A., Buchert, R., Andresen, B., Petersen, K., \& Thomasius, R. (2002).

Specific neurotoxicity of chronic use of ecstasy. Toxicology Letters, 127, 285-297.

Olney, J.W., Labruyere, J., Wang, G., Wozniak, D.F., Price, M.T., \& Sesma, M.A. (1991). NMDA antagonist neurotoxicity: Mechanism and prevention. Science, 254, 1515-1518.

Parrott, A.C. (2001). Human psychopharmacology of ecstasy (MDMA): A review of 15 years of empirical research. Human Psychopharmacology: Clinical and Experimental, 16, 557-577. 
Parrott, A.C. (2004). Is ecstasy MDMA? A review of the proportion of ecstasy tablets containing MDMA, their dosage levels, and the changing perceptions of purity.

Psychopharmacology (Berl), 173(3-4), 234-41.

Parrott, A.C., Lees, A., Garnham, N.J., Jones, M., \& Wesnes, K. (1998). Cognitive performance in recreational users of MDMA or "ecstasy": Evidence for memory deficits. Journal of Psychopharmacology, 12, 79-83.

Pihl, R.O., \& Peterson, J.B. (1995). Alcoholism: The role of different motivational systems. Journal of Psychiatry \& Neuroscience, 20, 372-396.

Pope, H.G., Gruber, A.J., Hudson, J.I., Cohane, G., Heustis, M.A., \& Yurgelun-Todd, D. (2003).

Early-onset cannabis use and cognitive deficits: What is the nature of the association? Drug and Alcohol Dependence, 69, 303-310.

Pope, H.G., Gruber, A.J., Hudson, J.I., Huestis, M.A., \& Yurgelun-Todd, D. (2001).

Neuropsychological performance in long-term cannabis users. Archives of General Psychiatry, $58,909-915$.

Reneman, L. (2000). Memory disturbances in "Ecstasy" users are correlated with altered brain serotonin neurotransmission. Psychopharmacology, 148, 322-324.

Reneman, L., Booji, J., de Bruin, K., Reitsma, J.B., de Wolff, F.A., Gunning, W.B., den Heeten, G.J., \& van den Brink, W. (2001). Effects of dose, sex and long-term abstention from use on toxic effects of MDMA (ecstasy) on brain serotonin neurons. Lancet, 358, 1864-1869.

Reneman, L., Majoie, C.B., Flick, H., \& den Heeten, G.J. (2002). Reduced N-acetylaspartate levels in the frontal cortex of MDMA (Ecstasy) users: Preliminary results. American Journal of Neuroradiology, 23, 231-237.

Ricaurte, G.A., DeLanney, L.E., Irwin, I., \& Langston, J.W. (1988). Toxic effects of MDMA on central serotonergic neurons in the primate: Importance of route and frequency of drug administration. Brain Research, 446, 165-168.

Ricaurte, G.A., Yuan, J., Hatzidimitriou, G., Cord, B.J., \& McCann, U.D. (2002). Severe 
dopaminergic neurotoxicity in primates after a common recreational dose regimen of

MDMA (“ecstasy”). Science, 297, 2260-2263.

Ricaurte, G.A., Yuan, J., Hatzidimitriou, G., Cord, B.J., \& McCann, U.D. (2003). Retraction:

Severe dopaminergic neurotoxicity in primates after a common recreational dose regimen of MDMA (“ecstasy”). Science, 301, 1479.

Rodgers, J., Buchanan, T., Scholey, A., Heffernan, T., Ling, J., \& Parrott, A. (2001). Differential effects of Ecstasy and cannabis on self-reports of memory ability: A web-based study. Human Psychopharmacology: Clinical and Experimental, 16, 619-625.

Sabol, K.E., Lew, R., Richards, J.B., Vosmer, G.L., \& Seiden, L.S. (1996). Methylenedioxymethamphetamine-induced serotonin deficits are followed by partial recovery over a 52-week period. Part I: Synaptosomal uptake and tissue concentrations. Journal of Pharmacology and Experimental Therapeutics, 276, 846-854.

Simon, N.G., \& Mattick, R.P. (2002). The impact of regular ecstasy use on memory function. Addiction, 97, 1523-9.

Taffe, M.A., Weed, M.R., Davis, S., Huitron, S., Shroeder, R., Parsons, L.H., Henriksen, S.J., \& Gold, L.H. (2002). Functional consequences of repeated MDMA treatment in rhesus monkeys. Neuropsychopharmacology, 24, 230-9.

Tarter, R.E., Moss, H.B., \& Vanyukov, M.M. (1995). Behavioral genetics and the etiology of alcoholism. In H. Begleiter \& B. Kissin (Eds.), The genetics of alcoholism (pp. 294-326). New York: Oxford University Press.

Thomasius, R., Petersen, K., Buchert, R., Andresen, B., Zapletalova, P., Wartberg, L., Nebeling, B., \& Schmoldt, A. (2003). Mood, cognition and serotonin transporter availability in current and former ecstasy (MDMA) users. Psychopharmacology, 167, 85-96.

Verbaten, M.N. (2003). Specific memory deficits in ecstasy users? The results of a meta-analysis. Human Psychopharmacology: Clinical and Experimental, 18, 281-290.

Virkkunen, M., \& Linnoila, M. (1997). Serotonin in early-onset alcoholism. In M. Galanter (Ed.), 
Recent developments in alcoholism, volume 13: Alcohol and violence (pp. 173-189). New York:

Plenum Press.

Vollenweider, F.X., Jones, R.T., \& Baggott, M.J. (2001). Caveat emptor: Editors beware.

Neuropsychopharmacology, 24, 461-463.

Wareing, M., Fisk, J.E., \& Murphy, P.N. (2000). Working memory deficits in current and previous users of MDMA (“ecstasy”). British Journal of Psychology, 91, 181-188.

Winsauer, P.J., McCann, U.D., Yuan, J., Delatte, M.S., Stevenson, M.W., Ricaurte, G.W., \& Moerschbaecher, J.M. (2002). Effects of fenfluramine, m-CPP and triazolam on repeat-acquisition in squirrel monkeys before and after neurotoxic MDMA administration. Psychopharmacology (Berlin), 159, 388-396.

Zakanis, K.K., \& Young, D.A. (2001a). Executive function in abstinent MDMA (“ecstasy”) users. Medical Science Monitor, 7, 1292-1298.

Zakzanis, K.K., \& Young, D.A. (2001b). Memory impairment in abstinent MDMA (“ecstasy”) users: A longitudinal investigation. Neurology, 56, 966-969.

Zakzanis, K.K., Young, D.A., \& Campbell, Z. (2003). Prospective memory impairment in abstinent MDMA (“ecstasy”) users. Cognitive Neuropsychiatry, 8, 141-153. 

methodological issues. Drug and Alcohol Review, 25(3), 269-276. https://doi.org/10.1080/09595230600657758

This article may be used for non-commercial purposes in accordance with Wiley Terms \& Conditions for Use of Self-Archived Versions. 